\title{
A COMPARATIVE ANALYSIS OF ELECTRONIC AND TRADITIONAL LEARNING
}

\author{
NEBOJŠA DENIĆ ${ }^{1}$, MERDAN ZEJNELAGIĆ ${ }^{2}$, NATAŠA KONTREC ${ }^{\mathbf{1}^{*}}$ \\ ${ }^{1}$ Faculty of Sciences and Mathematics, University of Priština, Kosovska Mitrovica, Serbia \\ ${ }^{2}$ Faculty of information technology, Alfa BK University, Belgrade, Serbia
}

\begin{abstract}
Modern way of living and functioning of human society requires a new principle of decision making and adjusting to contemporary living needs. In times when humans have perfected the contemporary living needs with their technological achievements yet another disadvantage among those needs has appeared. Studying possibilities and adjusting to educational requirements have hardly made any progress in years. Traditional learning methods are implemented by means of book, pencil and paper, as was the case thousands of years ago, supporting functioning of human society. This paper, based on researches founded on implementation of educational software and researches founded on postulates of implementation of frontal education and summarizing related specialized literature from this area, will set forth possibilities for implementation of information and communications technologies (ICT) and educational software in teaching. The results of this research indicate that the students who were using electronic methods of learning in combination with traditional learning had become more motivated, skilled and interested in a new way of thinking that activates all senses in order to form their intellectual personality.
\end{abstract}

Keywords: Teaching, Education, Electronic learning.

\section{INTRODUCTION}

Today, one of the most challenging tasks is the improvement of methods of traditional learning. A need to improve these methods originates from this fact that traditional learning represents an improper bond between knowing and recognizing for both the individual and the society. The majority of modern society frowns upon learning for personal gains. On those bases, an idea to improve traditional learning methods occurred, in order to develop a literate and technologically functional society with the use of modern technologies (Denic \& Petković, 2018). Distance learning represents an educational process with no limitations, obstacles and interferences, and as such, it is available to everyone and at all times, by means of modern technologies and mass media with the aim of supporting the process of education and gaining new knowledge, and offers a two-way possibility for communication as a social and interactive tool, which is one of the most important reasons for improving the traditional methods of education. Distance education has been extensively researched in (Moor et al., 2011; Anderson, 2008; Moore \& Kearsley, 2005; Keegan, 2005; Simonson, 2001; Simonson \& Schlosser, 2004; Keegan, 1996). As agreed by most authors, the description and scope of learning has been regenerated and improved over the years (Chawinga \& Zozie, 2016), so we can state with certainty that the modern learning method is founded upon understanding the fact that students and teachers need not be present in the same premises but their interaction can be established from a distance with the

* Corresponding author: natasa.kontrec@pr.ac.rs

MATHEMATICS, COMPUTER SCIENCE AND MECHANICS assistance offered by ICT (Denić et al., 2017b; Chawinga \& Zozie, 2016; Moore \& Kearsley, 2004). However, the most widely accepted definition of electronic learning, on which this paper is founded upon, describes the electronic lesson as an interactive possibility for transfer of teacher's knowledge so that he can, based on his personal devotion and syllabus' design, provide prompt, anticipated and motivated effort for adoption of the aforementioned knowledge (Moor et al., 2011). E-learning continuum is presented in Figure 1.

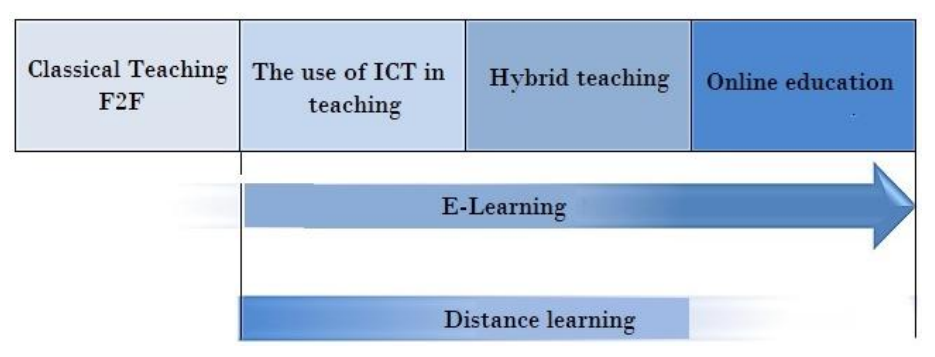

Figure 1. E-learning continuum.

\section{QUALITY IN TEACHING BASED ON ICT}

High quality ICS (Information Communication System) is comprised of institutions that commonly belong to another subsystem (educational institution, Ministry of Education, state), and connectivity channels that provide an unobstructed flow of information within the system (exchange of data, mail on teacher-student relation, notices) and communicators that proficiently and regularly update the materials within the system (teachers) (Hassanzadeh et al., 2012). Education based on ICT is for the most part more meaningful, interesting and of higher 
quality (Denić et al., 2014). Each student can practically and actively take part in lecturing and in this manner achieve required level of recognition by teachers. The quality of design directly affects the quality of lecturing and is one of the most important factors for high quality educational content. The content comprises entire material included in educational process, as well as additional materials designed by students and teachers together and by doing so, enrich the educational content. These entities and their interaction can be illustrated in a didactic triangle (Figure 2).

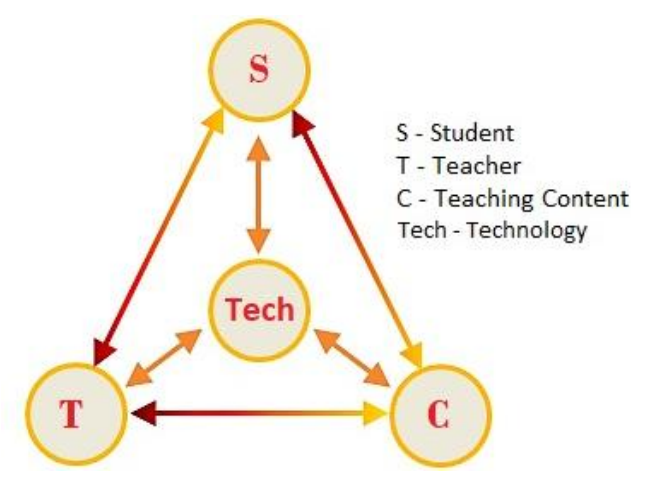

Figure 2. Didactic triangle.

Elementary and high school education, besides aiming at gaining of knowledge, is founded upon developing of students' intellectual capabilities, individual decision making as well as developing their abilities for additional improvements (Denić et al., 2014). In academic education and post-academic studies, elearning provides immeasurable contributions to all spheres of education and directly affects improvement of quality of teaching and quality of education. Professors, lecturers and teachers contribute significantly to quality of education with their extracurricular activities and directly affect the society's general education. High quality extracurricular content contains good graphic quality and understandable multimedia content (text, sound, image, video, animation). Extracurricular content must be connected and adjusted with the content of the educational institution. ICT unify concepts of education and technologies into one. However, the concept of electronic learning is repeatedly misunderstood. Electronic learning has the goal to improve the meaningfulness of education, add up missed knowledge and enable enhancing of the traditional knowledge with practical part of education, but not to take over the leading role in education. In a narrower sense, electronic learning is more comprising, practical and broader than traditional method of learning, but electronic learning without traditional method of learning (required explanation and interpretation by teachers) almost has no major advantage in science. In many occasions we have witnessed that pupils of elementary and high schools that posses high quality and comprising ICS manage to achieve remarkable success at national and international level competitions and knowledge Olympics. In comparison, the difference in educational content is minor. Teachers who pass the knowledge stick to the same or similar teaching educational system. Pupils of same age often have similar intellectual capabilities. The advantage of success is in additional material that can easily be transferred in a high quality ICS (Denić et al., 2017a). Therefore, once solved task is being kept and updated in electronic classroom, where every next generation of students has the opportunity to enhance this solved task and use it as an example in practice, and each reprocessed task is preserved and with the teacher's meticulousness gets re-updated in the database, leaving high quality content for new success in the related area for generations to come. E-learning surroundings is comprised of a Learning Management System (LMS), a Content Management System (CMS) and a Knowledge Management System (KMS) and some of the tools for content authorization (Gavrilović et al., 2018; Babu, 2005; Moore et al., 2011; WilenDaugenti, 2009). E-learning surrounding is an informational system (IS) based on World Wide Web (Lee \& Lee, 2008).

\section{RESEARCH DESCRIPTION}

Improving of living needs for both individual human beings and society in general is one of the hot topics in modern times. $21^{\text {st }}$ Centuries advanced achievements have made impact on improvement of all aspects of life. Modern medicine, industry, economy, technology, in one word everything that surrounds us is related to information technologies and computers. ICT with the use of computer systems and IT equipment have improved all needs of human society. Whether it concerns military equipment, medical lasers, industrial machines, means of transport, satellites (everything that surrounds us) is controlled by a computer today. Computers have used their endless possibilities to a limited extent in education. Improvement of modern education as well as creating an interactive educational content represents an endless treasury for education of modern people. Today, there is a large number of elementary and high schools in our surroundings, that still base their lectures on traditional methods of education. Also, there is not a single student who has not met with or has not used a modern computer. IT generation of people is represented by people who have been in contact with computers from the day they were born. Computers are both the need and the object of interest by people.

Testing is a possibility to check the students' knowledge on all levels. It is conducted with the use of previously designed questions in written or electronic form. Testing represents a way to assess the students' abilities and knowledge. The use of modern technologies also resulted in a possibility to learn through testing. Testing with the use of computers presents an educational experience and a better educational possibility. The possibility to learn on students' mistakes brings additional stimulus and will for further improvement. Electronic testing has the greatest social contribution in modern psychology. Electronic testing represents a method of modern assessment of human abilities. By means of electronic testing and learning, the wrong 
answer no longer represents an obstacle for decision making, but instead it encourages the user to learn from own mistakes. The wrong answers will provide the user with the dual experience in education. He will learn what the correct answer to a question is but also what the wrong answer to a question is. The related researches have shown that humans are capable of remembering $20 \%$ of information he/she had heard, $40 \%$ of information he/she had both seen and heard, and $75 \%$ of information he/she had seen, heard and actively implemented in practice.

For the needs of this paper, the pupils of $5^{\text {th }}, 6^{\text {th }}, 7^{\text {th }}$ and $8^{\text {th }}$ grade of an elementary school in Kosovo and Metohija have been tested. The questions were designed with the goal to improve intellectual and sensory capability of pupils. Intellectual capabilities are: analysis, synthesis, abstract opinion, ability to reach a conclusion, dealing with terminology, use of symbols and terms, recognizing similarities as well as prompt thinking etc. Sensory abilities include hearing, seeing, rapid response and replying etc. The questions are grouped into different areas, as follows:

- Knowledge of hardware, software and computers;

- Educational issues;

- Operating system and its components;

- Structural issues;

- Windows applications;

- Computer networks;

- General issues.

Based on books used in elementary schools, a database with questions was created, and pupils who have successfully finished the $5^{\text {th }}$ grade were tested with ten randomly selected questions. The answers were divided into five groups, as follows:

+ the pupil recalls the teaching content satisfactorily;

0 the pupil recalls the teaching content superficially;

- $\quad$ the pupil needs to be reminded of the teaching content;

I the pupil has difficulties recalling the teaching content.

After testing of pupils who had successfully completed the $5^{\text {th }}$ grade of elementary school, the pupils of the $6^{\text {th }}, 7^{\text {th }}$ and $8^{\text {th }}$ grade of elementary school were tested.

\section{RESEARCH RESULTS}

The research conducted on ten pupils who had completed the fifth grade in different elementary schools, provided the results presented in Table 1 and Figure 3.

The research indicated that the pupils who have been using the traditional method of learning have forgotten a significant part of content and needed to be reminded of this content. The content that they have been learning in elementary schools was to some extent interesting and less creative. When asked what their biggest incentive in learning was, most of them pointed out knowledge of computers and computer equipment.

Table 1. Test results of pupils who had completed the $5^{\text {th }}$ grade in 2016/17 school year.

\begin{tabular}{|l|c|c|}
\hline List of pupils & Class & Answer \\
\hline Pupil 1 & 5. & 0 \\
\hline Pupil 2 & 5. & - \\
\hline Pupil 3 & 5. & + \\
\hline Pupil 4 & 5. & 0 \\
\hline Pupil 5 & 5. & 0 \\
\hline Pupil 6 & 5. & $/$ \\
\hline Pupil 7 & 5. & 0 \\
\hline Pupil 8 & 5. & - \\
\hline Pupil 9 & 5. & + \\
\hline Pupil 10 & 5. & 0 \\
\hline
\end{tabular}

Table 2. Test results of pupils who had completed the $7^{\text {th }}, 8^{\text {th }}$ and $9^{\text {th }}$ grade in $2016 / 17$ school year.

\begin{tabular}{|l|c|c|}
\hline List of pupils & Class & Answer \\
\hline Pupil 1 & 7. & 0 \\
\hline Pupil 2 & 6. & - \\
\hline Pupil 3 & 7. & 0 \\
\hline Pupil 4 & 8. & 0 \\
\hline Pupil 5 & 8. & + \\
\hline Pupil 6 & 8. & - \\
\hline Pupil 7 & 6. & $/$ \\
\hline Pupil 8 & 7. & $/$ \\
\hline Pupil 9 & 7. & - \\
\hline Pupil 10 & 6. & - \\
\hline
\end{tabular}

Research results for pupils who had completed the fifth grade in 2016/17

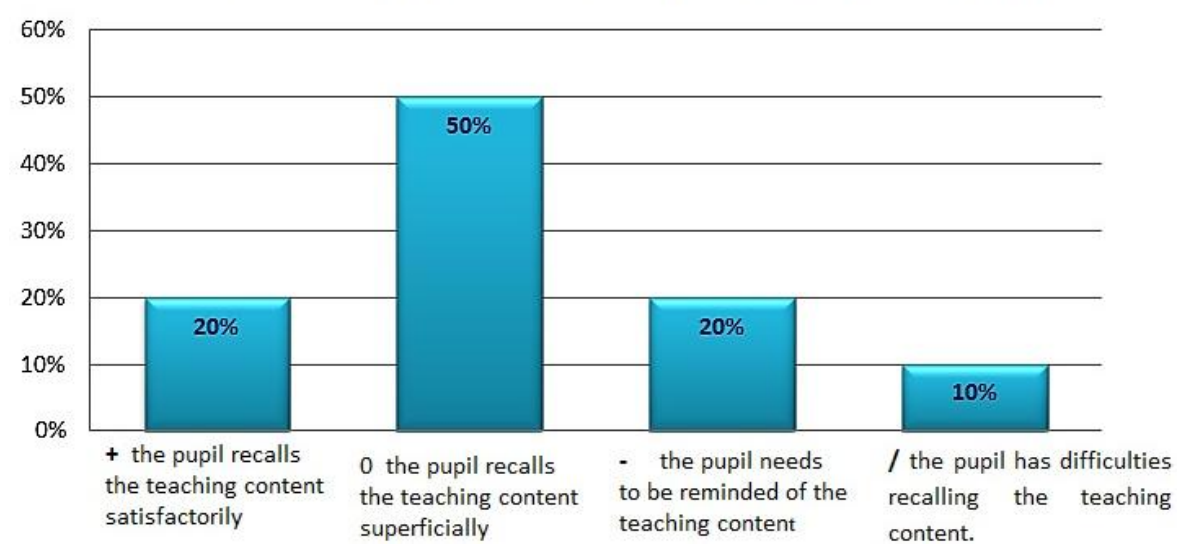

Figure 3. Research results for $5^{\text {th }}$ grade students in $2016 / 17$. 
The second research, conducted on ten pupils who had completed the fifth grade of elementary school and attended the $6^{\text {th }}, 7^{\text {th }}$ and $8^{\text {th }}$ grade, indicated the results presented in Table 2 and Figure 4.

The survey has shown that the pupils have no permanent memory of the knowledge gained in this manner but need a shorter time period to recall the tasked area. The content they had studied in elementary schools was interesting but not creative enough. When asked what was their biggest incentive in learning most of them agreed the reason was the overall possibilities of computers and internet. Based on the conducted survey we can easily reach a conclusion that the method for designing educational content is outdated, flawed and non-interactive. During the entire course of the lectures, a pupil is only offered dry material with necessary typical exercises which only activate recognizing of practical knowledge to a certain extent.

Research results for pupils who completed 6th, 7th and 8th grade in 2016/17

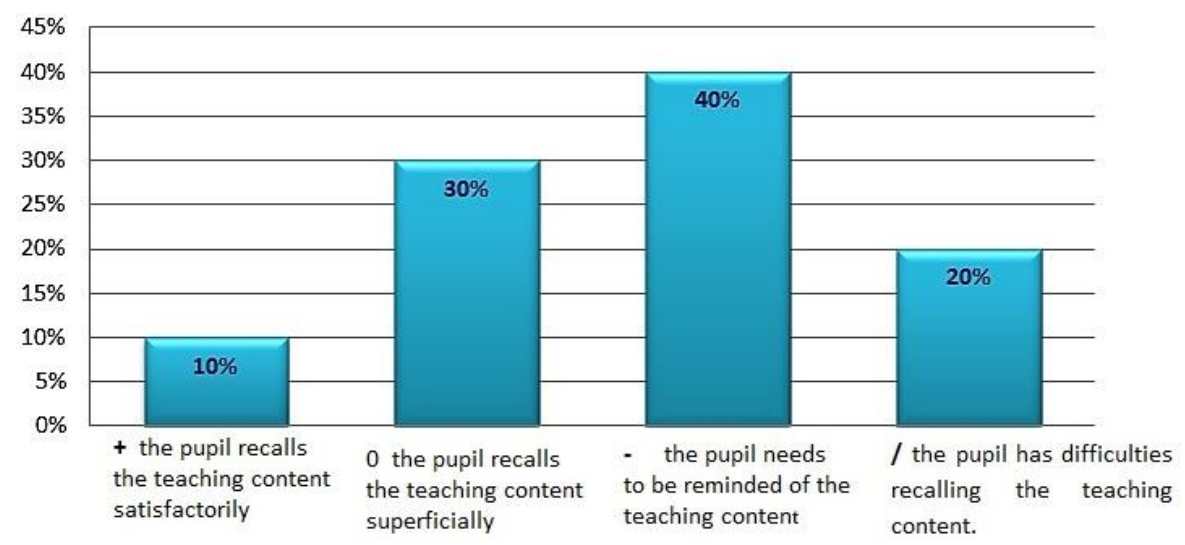

Figure 4. Research results for $6^{\text {th }}, 7^{\text {th }}, 8^{\text {th }}$ grade students in $2016 / 17$.

\section{INTRODUCING STUDENTS WITH SOFTWARE FOR ELECTRONIC LEARNING AND THEIR SURVEY RESULTS}

After completing the survey, each student had a possibility to solve the interactive test with the help of SmartNotebook 17.0 application. All students were divided into pairs and were solving the same test. The test was consisted of 10 new questions. Each student understood the rules of the competition in prompt and simple way and afterwards completed the final survey (Table 3). With its audio and video effects, the application awoke attention of all surveyed pupils and enticed them to think creatively. After successful completion of the quiz, the students had a possibility to get acquainted with other questions from the offered database. The acquainting had the purpose to have the pupils assess the application subjectively.

The pupils completed the survey with the following offered responses:

- 0 - I think that the offered application is useless for my studying;

- 1 - I think that the offered application is inapplicable for my studying;

- $\quad 2$ - I think that the offered application is a solid base for my studying;

- 3 - I think that the offered application is creative for my studying;

- 4 - I think that the offered application is useful for my studying;
- 5 - I think that the offered application is ideal for my studying.

Table 3. Final survey on content quality of Smart Notebook application and its implementation in practice.

\begin{tabular}{|l|l|l|}
\hline $\begin{array}{l}\text { List of } \\
\text { pupils }\end{array}$ & Class & Mark \\
\hline Pupil 1 & 6. & 3 \\
\hline Pupil 2 & 6. & 4 \\
\hline Pupil 3 & 6. & 4 \\
\hline Pupil 4 & 6. & 5 \\
\hline Pupil 5 & 6. & 5 \\
\hline Pupil 6 & 6. & 4 \\
\hline Pupil 7 & 6. & 3 \\
\hline Pupil 8 & 6. & 5 \\
\hline Pupil 9 & 6. & 4 \\
\hline Pupil 10 & 6. & 4 \\
\hline Pupil 11 & 7. & 5 \\
\hline Pupil 12 & 6. & 5 \\
\hline Pupil 13 & 7. & 4 \\
\hline Pupil 14 & 8. & 5 \\
\hline Pupil 15 & 8. & 3 \\
\hline Pupil 16 & 8. & 2 \\
\hline Pupil 17 & 6. & 3 \\
\hline Pupil 18 & 7. & 5 \\
\hline Pupil 19 & 7. & 5 \\
\hline Pupil 20 & 8. & 5 \\
\hline
\end{tabular}




\section{Research results on implementation of e-learnig softwere in education}

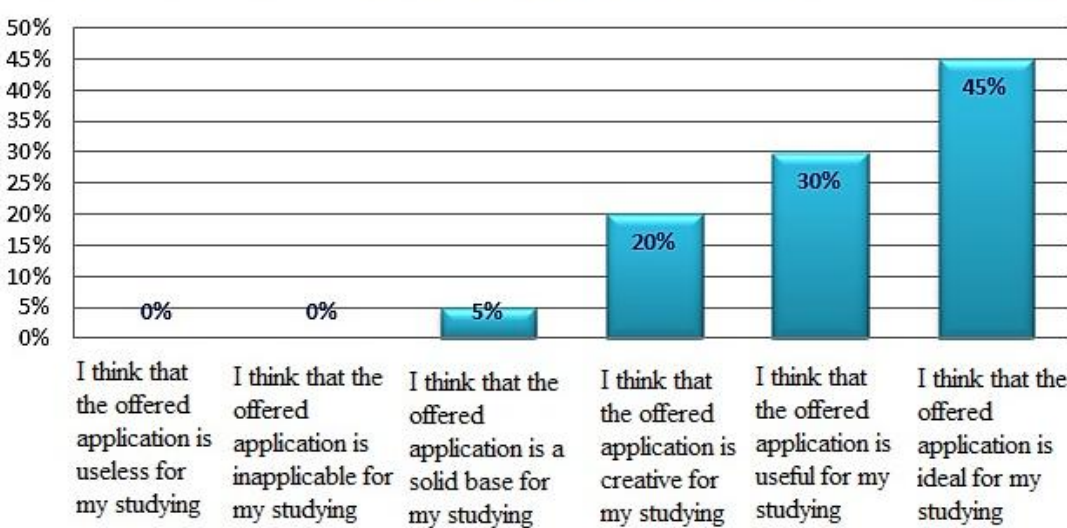

Figure 5. Research results on implementation of e-learning in education.

Based on the conducted research we have received the following results on implementation of Smart Notebook application in contemporary education of pupils, as in Figure 5.

Based on the overall research and interest from the pupils for modern technologies and possibilities for achieving adequate goals in contemporary education of pupils we can safely say that software for electronic learning have positive effect on the pupils' creative thinking. They proved useful in surmounting the tasked content at hand and with adequate implementation along with the traditional method of learning assist in overall pupils' education. A pupil can overcome the tasked areas through fun and play, make a subjective ruling on accuracy of the asked question and in that manner complete his/her own knowledge or enhance creative learning by learning from the wrong answer. The knowledge gained like this is more permanent than traditional learning. A pupil is given a possibility to select one of the offered answers and in this way his thinking can be adequately evaluated and guided to proper and mature thinking.

\section{CONCLUSION}

Modern education represents a vital precondition for continued existence and developing of a modern society. The ICT with its importance and connections to other sciences represents one of the most important factors for progress and enhancement of the human community needs. Today, information technologies represent one of more important subjects at all faculty departments. Whether we are talking about medicine, mathematics, physics, construction or other social sciences, the informatics has the leading role in their education and enhancement. Various software packages, with the assistance of computers, have found their use in implementation of very important and precise jobs for decades. The importance of IT education is in proportion with the importance of technological development of a modern society. Contemporary methods of learning and educating, such as electronic learning and distance learning, have provided access to the required knowledge to all people in need. With help of electronic learning, education can no longer be placed under the field of a traditional classroom. Global trends in education place electronic learning at one of the leading positions of modern education. A proper use of electronic learning can have immeasurable effects in education and teaching. However, we must be aware that internet and computers also have their downsides. Without adequate assistance by a competent lecturer some negative effects and hazards can also be experienced when information technologies are used in education. A well planned content of electronic learning is adjustable and applicable for the needs of each individual student. Whether it concerns hard working students, students less able to remember or handicapped persons, the electronic learning offers additional support in improving gaining of required knowledge. Beside its contribution to memorizing and adopting new information, the electronic learning also enables children to develop emotional and social skills. The education assisted by the electronic learning directly affects the students' behavior. Software used during lectures can be designed in various colors. Based on such display of information, both brain hemispheres are triggered and a student can remember and accept new information in an easier way. Practical lectures have shown that children who follow lectures designed on basis of multimedia content accept new information in an easier and faster way in comparison to children who learn by means of a traditional method of learning with books. The electronic learning has positive influence on manifold aspects of children's development. In a physical context, a hand-eyehearing relationship is developed, while in an intellectual context children have a possibility for better memorizing and enhancing team spirit skills, as well as developing their own memorizing skills. In the future, the electronic learning will represent a foundation in education, in both educational institutions and each individual child in particular.

\section{REFERENCES}

Anderson, T. 2008. The theory and practice of online learning. Canada: Athabasca University Press. 
Babu, N. S. C. 2005. Quality Assurance Framework for eLearning. India: ELEL Tech.

Chawinga, W. D., \& Zozie, P. A. 2016. Increasing Access to Higher Education Through Open and Distance Learning: Empirical Findings From Mzuzu University, Malawi. The International Review of Research in Open and Distributed Learning, 17(4). doi:10.19173/irrodl.v17i4.2409

Denić, N., Živić, N., \& Spasić, B. 2014. Application Of Information And Communication Techologies In School Education. Annals Of The Oradea University. Fascicle Of Management And Technological Engineering., XXIII (XIII)(3). doi:10.15660/auofmte.2014-3.3062

Denić, N., Nešić, Z., Radojičić, M., Petković, D., \& Stevanović, M. 2017a. Contribution to the research of children protection in use of interent. Tehnički vjesnik, 24, pp. 525-533.

Denić, N., Gavrilović, S., \& Kontrec, N. 2017b. Information and communications technologies in function of teaching process. The University Thought - Publication in Natural Sciences, 7(2), pp. 58-63. doi:10.5937/univtho7-15472

Denić, N., \& Petković, D. 2018. Obrazovni softver. Kosovska Mitrovica: Prirodno matematički fakultet. ISBN 978-8680795-36-2.

Gavrilović, S., Denić, N., Petković, D., Živić, N. V., \& Vujičić, S. 2018. Statistical evaluation of mathematics lecture performances by soft computing approach. Computer Applications in Engineering Education, 26(4), pp. 902-905. doi:10.1002/cae.21931

Hassanzadeh, A., Kanaani, F., \& Elahi, S. 2012. A model for measuring e-learning systems success in universities. Expert
Systems with Applications, 39(12), pp. 10959-10966. doi:10.1016/j.eswa.2012.03.028

Keegan, D. 1996. Foundations of distance education. London: Croom Helm.

Keegan, D., (Eds). 2005. Theoretical Principles of Distance Education.Informa UK Limited. doi:10.4324/9780203983065

Lee, J., \& Lee, W. 2008. The relationship of e-Learner's selfregulatory efficacy and perception of e-Learning environmental quality. Computers in Human Behavior, 24(1), pp. 32-47. doi:10.1016/j.chb.2006.12.001

Moore, M., \& Kearsley, G. 2011. Distance Education: A Systems View of Online Cengage Learning.

Moore, J. L., Dickson-Deane, C., \& Galyen, K. 2011. eLearning, online learning, and distance learning environments: Are they the same. The Internet and Higher Education, 14(2), pp. 129-135. doi:10.1016/j.iheduc.2010.10.001

Moore, M. G., \& Kearsley, G. 2005. Distance education: A systems view. Belmont, CA: Thomson Wadsworth.

Simonson, M. 2001. Distance education and online instruction: Profession or Field. The Quarterly Review of Distance Education, 2(4); 301-302.

Simonson, M., \& Schlosser, C. 2004. We Need A Plan, An Instructional Design Approach for Distance Education Courses. Fischler College of Education: Faculty Articles.

Wilen-Daugenti, T. 2009. Edu: Technology and Learning Environments in Higher Education. Peter Lang, International Academic Publishers. doi:10.3726/b11473 